\title{
IMMUNOLOGICAL ANALYSIS OF ABNORMALITIES IN THE HUMAN SERUM PROTEINS BY A GEL-DIFFUSION METHOD
}

\author{
BY \\ P. G. H. GELL \\ From the Department of Experimental Pathology, University of Birmingham
}

(RECEIVED FOR PUBLICATION MAY 2, 1955)

Immunological methods allow of a more precise discrimination between similar proteins or high-molecular-weight carbohydrates than any chemical or physical method; but they have in practice been little used in analysis. There are a number of reasons for this: only substances which are antigenic can be identified; the major component of a mixture may provoke less antibody than a contaminant, or none at all ; there is no simple way of correlating a precip tin reaction curve with the physical properties of the antigen molecule-shape, molecular weight, and so on ; quantitative estimation is a laborious and specialized technique ; furthermore there is no certainty that all the antibody measured has been brought down by the protein under investigation, rather than by contaminating antigen-antibody systems in the same optimal range.

The use of gel-diffusion methods such as those described below has altered this situation. It is now possible to identify a single line or "front" with near certainty as being due to a particular protein ; and, used with suitable precautions, this method of identification is far more specific and sensitive than any purely physico-chemical technique. It avoids the laboriousness and the uncertainties of immunological estimation, though it sacrifices its quantitative precision. However, quantitative estimates are possible, of a grade of accuracy usually sufficient for practical purposes.

The present study illustrates some clinical applications of the gel-diffusion method, with an approach to the problem of quantitative estimation. The method used is based on those of Ouchterlony (1948, 1949), Elek (1949), and Grabar (1954), in which the reagents diffuse towards one another from cups cut in agar in petri dishes.

Under these circumstances the reagents will meet at "optimal proportions" somewhere in the intervening space and a band of precipitate will occur there. If several antigen-antibody systems are present, several bands may develop, each corresponding with one antigen. If two differing preparations of antigen are placed in cups near one another, and both diffuse towards the antiserum, the lines due to proteins present in both will join at an angle, while if a particular protein is present in one but not in the other its characteristic line of precipitate will not be diverted (Fig. 1).

The methods using diffusion in test-tubes, such as those of Oudin (1946), Munoz and Becker (1950), and Oakley and Fulthorpe (1953), though giving well-marked band-patterns, do not allow of this side-to-side comparison of different preparations. Clearly with the petri dish method any convenient number of antigens can be arranged round the central antiserum cup, so that the lines due to a common antigen may join to form a polygon; in practice, with fairly strong antisera, eight or 10 is the maximum giving lines of reasonable length.

A further refinement of technique is the combination of micro-electrophoresis (Grabar and Williams, 1953) with gel-diffusion. In this method the antigenic components are first separated by an electrophoretic run in agar, and then the antiserum is allowed to diffuse towards them from a trough cut at a suitable distance.

These techniques have as yet hardly been applied to the study of pathological sera. Clearly they are most readily adapted to showing qualitative or gross quantitative changes, their chief merit for this purpose being their very high specificity. Within their limits - that is, the power of discrimination of the antibody-forming cells of the animal species producing antibodies-there can be no sort of doubt about the identity of the fractions in which alterations occur. In the case of human sera, the antisera used in this work differentiate normally some dozen serum components, and other lines can be identified in 

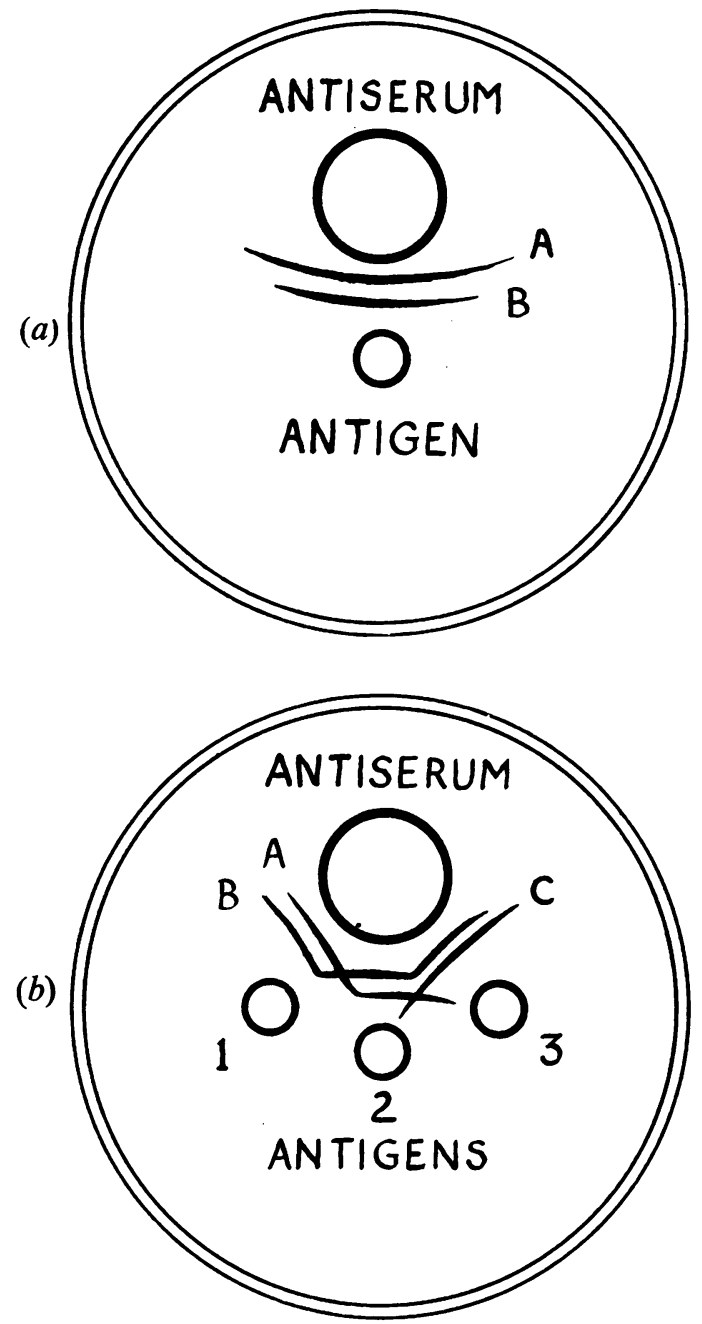

FIG. 1.-(a) Crude preparation of antigen (containing components A, B) diffuses towards antiserum where each pair meets as optimal proportions bands of precipitate form. (b) Three crude preparations of antigen diffuse towards antiserum-1 is seen to contain components A, B; 2 contains the same components but in different relative proportions since the lines join with those from $1 ; 3$ contains one common component $B$ and one fresh component $\mathrm{C}$.

special cases by the use of fractionated or " pathological" sera (see below). Grabar and Williams (1953) quote at least $15-17$ substances as being demonstrable. This very simple method for distinguishing so many different proteins can be used for analysis of pathological sera in large numbers, and may both throw light on the function of individual proteins and prove a more refined aid in diagnosis than paper electrophoresis alone.
Useful results have been obtained in the study of a- and hypo-gammaglobulinaemia, and promis- $\underline{\underline{ }}$ ing ones in nephrosis, multiple myeloma, etc.; some of these are described below.

\section{Technique}

Antisera.-These were raised in rabbits either by $\frac{\bar{\sigma}}{\bar{D}}$ the use of alum-precipitated antigens given intra- $\bar{\sigma}$ venously (Kabat and Mayer, 1948) or by subcutaneous $\varrho$ injections of emulsions made according to the method $\%$ of Freund and McDermott (1942). All sera are pre- $\vec{\circ}$ served with $0.02 \%$ sodium azide. The antigens used should in general be as crude as possible, that is, they $\vec{\omega}$ should contain all the proteins which will later need $\stackrel{\omega}{\circ}$ identification; special investigations will of course $\overline{ }$ call for partially purified antigens. Satisfactory antisera will contain of the order of $0.25 \mathrm{mg}$. precipitable nitrogen per $\mathrm{ml}$. Individual rabbits are exceedingly i diverse in the pattern of antibodies which they produce 8 to a multiple antigen, even if the total weight of anti- $\mathrm{O}$ body varies little, and there is some advantage in not bulking antisera but in keeping them separate.

Medium.-For protein antigens, agar is the most convenient medium. In this work New Zealand agar $\frac{\Phi}{3}$ (Davis) has been used throughout at $0.5-0.6 \%$, made up in phosphate buffer saline $(p H$ 7.4) containing sodium $\stackrel{\mathbb{Q}}{-}$ azide $(0.02 \%)$; this is filtered and poured in specially $\overrightarrow{0}$ selected flat-bottomed petri dishes to a depth of $3 \mathrm{mmg}$ o or care being taken to keep the dishes perfectly leve (Agar may be unsuitable for systems containing car bohydrate antigens, for obvious reasons.)

Setting up the Reaction.-For satisfactory results it is necessary to keep the arrangement of the cups strictly uniform : the exact dimensions will depend $\mathbb{D}$ upon the strength of the antiserum. With antisera of the antibody content quoted above, a distance of 10 to $12 \mathrm{~mm}$. between the edges of the antiserum and antigen cups, and about the same distance between the individual antigens, is sufficient for clear differentiation of the lines. With these distances the results can be read at 18 hours; if even a slightly greater? distance is allowed the time is sometimes considerably $\frac{5}{3}$ increased. Such dimensions allow a symmetrical arrangement of six to eight cups for antigens surrounding the antiserum cup.

It is convenient to cut the cups by means of cork-o borers; their size and distances apart can thus be varied at will, which is impossible if a template is used. It is not necessary to seal the bases of the cups. The nearer the reagents are together, the easier it is to get $N$ visible lines with weak or dilute antisera. At $4 \mathrm{~mm}$. N one drop of a strong antiserum diluted $1 / 32$ gives a $O$ clear line (Fig. 2). The limiting dilution of antiserum $\mathbb{\omega}^{N}$ is that which just gives a positive ring (interfacial) test.

Antigen Concentration.-For clear-cut lines it is $\frac{\mathscr{\Phi}}{\mathbb{D}}$ necessary that the total amount of antigen in each $\stackrel{\mathcal{C}}{+}$ cup should be approximately in "equivalent propor- 0 tions " to the total amount of antiserum, but a fairly wide variation is permissible (Fig. 3). If there are two $\vec{D}$ 
antigen-antibody systems present whose optimal ratios are very widely different, it may only be possible to bring one of them out satisfactorily. It is desirable in starting on any new batch of antiserum to put up a

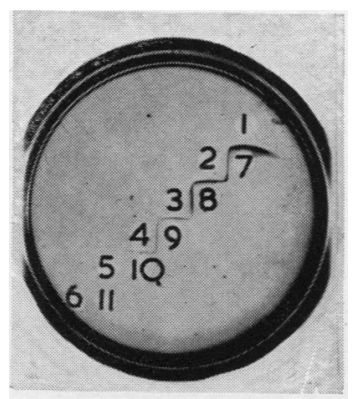

Fig. 2.-Limiting concentration of antibody. The cups 1-6 are filled with human serum albumin, decreasing by serial fourfold dilutions from $1 \%$ to $1 / 1024 \%$, the cups $7-11$ with antiserum at $1 / 1,1 / 4,1 / 16,1 / 64,1 / 256$ ( 2 drops of each): the distance from antigen to antiserum is $4 \mathrm{~mm}$. The limiting concentration of antibody under these circumstances is seen to be 2 drops of $1 / 64$, assuming that the reagents are at approximately optimal proportions.

plate containing serial dilutions of standard antigen against a standard volume. With most of the systems used in this work, 4-24 drops of antiserum, 1-4 drops of antigen (human serum, undiluted) at $11 \mathrm{~mm}$. gives a satisfactory general test of a pathological specimen. When the nature of the change is known the proportions can be altered, absorbed sera used, etc., to bring it out clearly and if possible quantitatively. Fig. 5 shows an example where the use of absorbed sera, and lesser distances, brings out with a very high degree of sensitivity the effects of therapy in a case of hypogammaglobulinaemia.

Identification of the Lines. - With human serum this is most conveniently done by means of fractions eluted from electrophoretic paper strips. The albumin and the $\gamma$-globulin can be easily identified with certainty in this way. The $\beta$-globulins form a "family" containing four members at least; this fraction is always contaminated with $\alpha_{2}$-globulin, which with our standard (rabbit) antiserum has always appeared to be a single entity, though Grabar and Williams (1953) using horse antisera find several. The $\alpha_{1}$-globulin has not been studied in this investigation. These identifications can be checked by means of a modification of the agar-electrophoresis method of Grabar and Williams (1953) as described below.

Quantitative Estimations. - The amount of antigen in a sample influences both the distance away that its line develops, and the density of the line. The distance is not at all sensitive to small alterations; in one system it was found that $2 \times$ changes in concentration had the effect of shifting the line one millimetre. However, it is often sufficient to know the order of concentration, particularly where one is investigating the deficiency of a protein-a research to which the method, because of its high sensitivity, is particularly applicable. Thus a side-by-side comparison of the pathological serum with normal serum at a known dilution or with a known concentration of $\gamma$-globulin (Fig. 4) gives a useful working estimate of the amount of $\gamma$-globulin present. More precise methods of estimation are described below. In the rare cases in which there is an absolute deficiency of a protein the method can be pushed to the limit of its sensitivity, and is far more sensitive than any other at present available (Fig. 6).

Recording and Preservation of Completed Reactions.-The photographs reproduced here were obtained by placing the petri dish on the horizontal lens of a Leitz projector and photographing the image on the screen; this is only practicable, however, with this type of projector. Attempts to photograph the reactions on a black background by obliquely transmitted light were only moderately successful.

It is quite easy to make the preparation permanent by fixing with formalin, washing thoroughly, removing

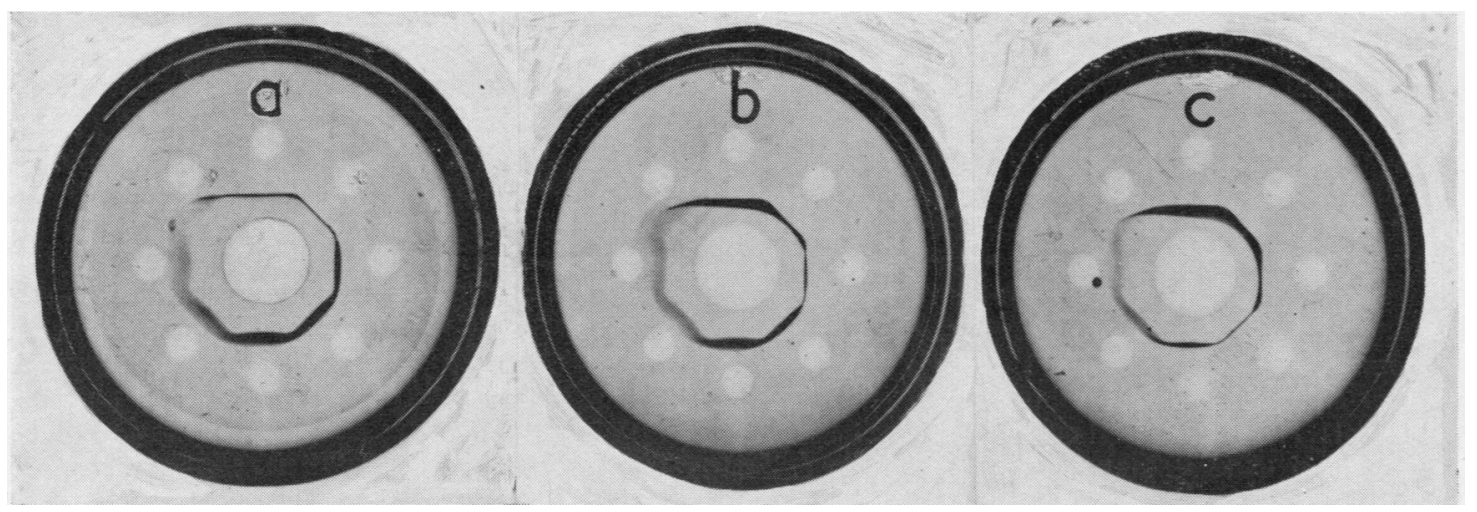

FIG. 3.-Optimal proportions. Three different amounts of antiserum ( $a, 16$ drops, $b, 8$ drops, $c, 4$ drops) against eight serial dilutions of antigen (human serum albumin: 4 drops of $1 \%-1 / 128 \%$ arranged clockwise starting at the top). The optimum (sharpest line) is clearly $1 / 2: 16$ drops, $1 / 4: 8$ drops, $1 / 8: 4$ drops. 


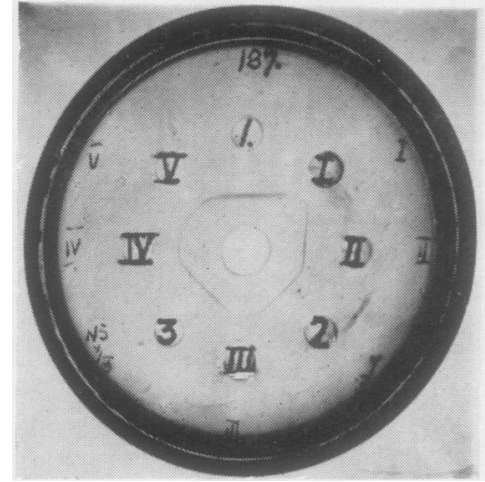

Fig 4.-1- and hypo-gammaglobulinaemia. (1) Normal human serum 11 . (2) $\gamma$-globulin $0 \cdot 3 \%$. (3) Normal human serum 310 . I, Patient G. P. (Grant and Wallace): " total a-gammaglobulinaemia." F., 23 yr. II, Patient P., F., 47 yr. III, Patient N., F., 33 yr. IV, Patient W. F., M., 3 yr. V, Patient H., F., 38 yr. The deficiency of $\gamma$-globulin in the samples of serum from patients II-V can be seen by the faintness of the line of precipitate and the decrease in its distance from the (antigen) source. The line from normal serum 11 is in "antigen excess" to the amount of antiserum present. There is no sign of the presence of any antigen in Serum I.

the agar slab, and drying it on a lantern slide. When completely dry the fainter lines disappear: the plates may either be stored dry and moistened for subsequent re-examination, or covered before they are quite dry with several coats of "betacryl $122 X$ " (I.C.I. Dyestuffs), a plastic soluble in xylene. The final coat of plastic might be oiled or varnished to render it impermeable to water.

Such preparations, if they are not too thick, give better results in a projector than a photographic lantern slide.

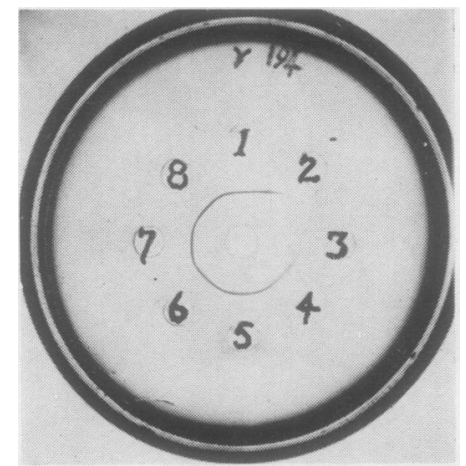

FIG. 5.-Effect of therapy on a case of hypogammaglobulinaemia. Case 4 (a boy of 3) had less than $0.05 \%$ gammaglobulin initially. He was given $0.5 \mathrm{~g}$. of gammaglobulin weekly for four months, during which time the serum $\gamma$-globulin rose to about $0.25 \%$. This figure illustrates this response to therapy. (1) $\gamma$-globulin (of the batch administered) $0.3 \%$; (2) patient's serum before start of treatment; (3) one week; (4) three weeks; (5) five weeks; (6) nine weeks; (7) 13 weeks; (8) normal serum $\frac{1}{3}$. The antiserum has been "adsorbed" (with the serum of Case 1) and reacts only with $\gamma$-globulin.

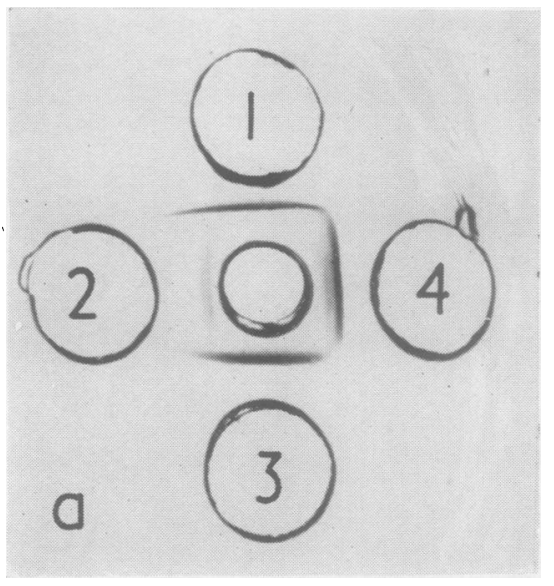

FIG. 6.-A-gammaglobulinaemia. These two reactions demonstrate a more rigid test on the serum of Case 1 for traces of $\gamma$-globulin. (a) 1, Normal serum 1:100. 2, Serum, Case 1. 3, Serum, Case 2. 4. Serum, Case 3. While Cases 2 and 3 show more $\gamma$-globulin than normal serum at 1100 (their lines are further from the antigen source), there is still no sign of a junction with any line from the serum of $C$ ise 1 (the other lines visible are due to minor globulins). (b) 1, 2, normal serum at $1 / 1,000 ; 3$, normal serum at $1 / 10,000 ; 4$, serum, Case 1 . Compared with (a) the antiserum has been diluted 1/10; distance is $2 \mathrm{~mm}$. There is still no sign of any deviation of the $;$-line, i.e., the amount of $\gamma$-globulin present in Case 1 serum is (if any) less than 1 1,000 of the normal, but, since $O$ normal serum at 110,000 is too weak to react at all, there may be the equivalent of this amount at least present.

\section{Illustrative Cases}

Hypogammaglobulinaemia.-Cases of this syndrome are being more frequently found with the increasing use of paper electrophoresis in clinica! laboratories. Fig. 4 shows a routine test on the serum of five cases, in four of which $\gamma$-globulin is shown to be present though reduced in amount, while in one (Case 1) it appears to be absent entirely. This case has been described by Grant and Wallace (1954) (to whom my thanks are due for the supply of samples): at the highest antiserum dilution practicable no suggestion of a $\gamma$-globulin line was found.

Patients with hypogammaglobulinaemia usually present as recurrent pneumonia, bronchiectasis, mastoiditis, etc., the deficiency of $\gamma$-globulin being correlated with a deficiency in antibody defences. Of the cases from which serum samples have been examined here, four (Cases 1, 2, 3, 5) were in adult females, and one in a boy of 3 (Case 4). In all except Case 1 there is some indication from the history that the condition was not present at birth ; in the child the first evidence of deficiency appeared at the age of 1 , in Cases 2 , 3 , and 5 during the 20 s or late 'teens. None of the cases had any signs of deficiency of the 
lymphoid system, as far as could be ascertained by clinical examination and blood counts. A number of cases of this syndrome have recently been described in Europe and the U.S.A. (Bruton, 1952; Young and Wolfson, 1954 ; Janeway, Apt, and Gitlin, 1953), some with and some without changes in lymphoid tissue.

Treatment is directed towards replacement of the absent antibodies, either with plasma, or preferably, because of the lesser risk of jaundice, with purified $\gamma$-globulin. These materials usually contain a sufficient titre of antibodies against the commoner infections to afford a reasonable measure of protection. Janeway et al. (1953) state that a blood level of 0.1 to $0.15 \% \quad \gamma$-globulin is necessary to obtain therapeutic results. This is about the limit of sensitivity for paper electrophoresis, and quantitative results are hardly possible. Fig. 5 shows the effect of therapy and Fig. 7 an attempt at quantitative immunological estimation: in the original plate at least there was

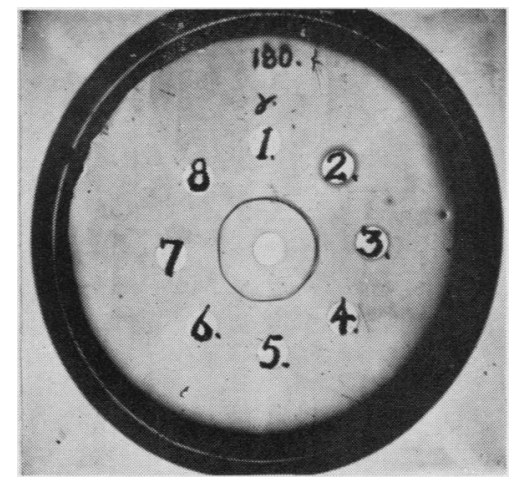

FIG. 7.-Quantitative estimation of $\gamma$-globulin. "Reference" (1) $\gamma$-globulin, (2), (3), (4), (5), (6), (7), (8) volumes of serum from Case 4 on 14/3 which if matched with (1) give equivalent concentrations of $0.1,0.15,0.2,0.25,0.3,0.35,0.4$ (approx.). The three reactions, $2,3,4$, on the right are definitely in " antigen excess" (the first interferes with the precision of part of the " reference" line): careful comparison of the characteristics of the lines on the original plate showed that (6) gave the best match to the density and sharpness of (1). It has not been possible to bring this out convincingly in the photograph.

no doubt, from comparison of the density and d'ffuseness of the lines, that 0.25 to $0.30 \% \gamma$-globulin was equivalent to the concentration in the serum under test. This sample was obtained from the child of 4 (Case 4), who was being treated with $0.5 \mathrm{~g}$. of $\gamma$-globulin intramuscularly once a week ; the sample was taken just before an injection, and, since it represented presumably a minimum concentration, the treatment had evidently satisfied the criterion of Janeway et al. quoted above.
Comparison of Serum and Urinary Proteins in Nephrotic Syndrome.-Another clinical condition in which the specificity of the immunological method is of value is in the examination of the urine in proteinuria. Fig. 8 shows the result of a parallel examination of urine and serum in two

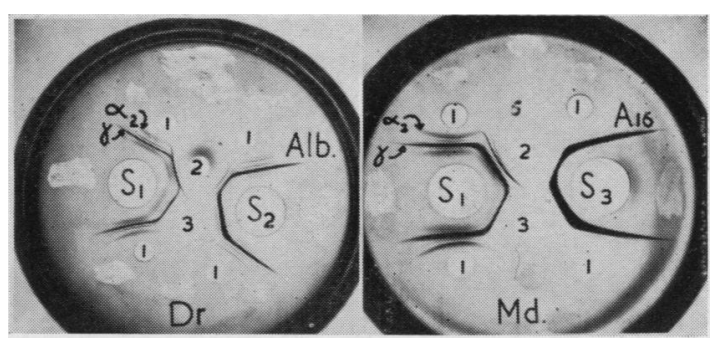

FIG. 8.-Nephrotic syndrome: serum and urire proteins. The serum and urine of two cases ( $\mathrm{Dr}, \mathrm{Md})$ of nephrotic syndrome analysed with the assistance of three antisera: $S_{1}$ reacting with $\gamma$-globulin, $a_{2}$-globulin and some others (but not albumin), the others $\left(\mathrm{S}_{2}, \mathrm{~S}_{3}\right)$ reacting mainly with albumin. (1) Normal serum 1 vol. (2) Patient's serum 1 vol. (3) Patient's urine 2 vol. In both plates $\alpha_{2}$-globulin appears to be absent from the urine: $\gamma$-globulin is present in both, and albumin is in very high concentration in the urines and deficient in the sera.

cases of the nephrotic syndrome. The urinary threshold of excretion closely parallels the molecular weights, $\alpha_{2}$, and to a lesser extent $\gamma$, being retained in the serum, and albumin appearing in high concentration in the urine.

This figure also demonstrates the antigenic identity of the urinary and the serum proteins. As far at least as the rabbit antibody-producing system can discriminate, the process of excretion does not appear to have had any deleterious effect upon the protein molecules.

Serum Protein Abnormalities in Multiple Myelomatosis.-Fig. 9 shows the results obtained with myeloma sera and the antisera raised against them. Fig. 9a shows the results with a " $\gamma$-myeloma" with a typical electrophoretic picture : here the increased $\gamma$ is evident in both the homologous and the heterologous (anti-normal-serum) reactions, i.e., the increase is due to excess of serologically normal $\gamma$-globulin, though whether the $\gamma_{1-}$ or $\gamma_{2}$-fractions are involved is not shown by this method. In the $\beta$-myeloma the reaction with anti-normal-serum shows no marked deviation from the normal pattern, though the proportions of some of the components are changed, but the homologous reaction shows the presence of a strong antigenic component, apparently absent from normal serum, though further analysis suggests that the antibody produced cross-reacts with one of the normal $\beta$-globulins.

Finally Fig. 10 shows the reactions of a serum which contains a globulin of an unusual kind. This substance was precipitated on dilution of the serum 


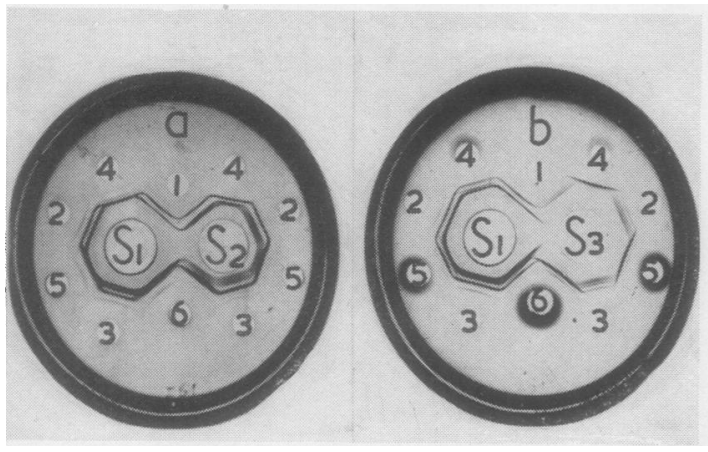

FIG. 9.-Multiple myeloma. (a) "Ganma myeloma" (Case Ou). $1,2,3=$ Normal serum, $4,5,6=$ myeloma $(\mathrm{Ou})$ serum, at $\frac{1}{2}, 1$. and 2 drops respectively. $S_{1}=$ Antiserum raised against normal human serum, reacting mainly with $\gamma$-globulin (outer strong line) and albumin. $S_{2}=$ Antiserum raised against serum of myeloma patient $(\mathrm{Ou})$ : reactions similar. (b) Beta myeloma (Case $\mathrm{Pk}$ ). Arrangement as in (a), but the serum used is from Case Pk and the antiserum $\mathrm{S}_{3}$ was raised against this. The reactions of sert $\mathrm{m}$ Pk with "anti-normal-serum" are much the same as those of serum $\mathrm{Ou}$ in $\mathrm{A}$, but reaction with the homologous $S_{3}$ reveais the presence of an apparently " specific" component.

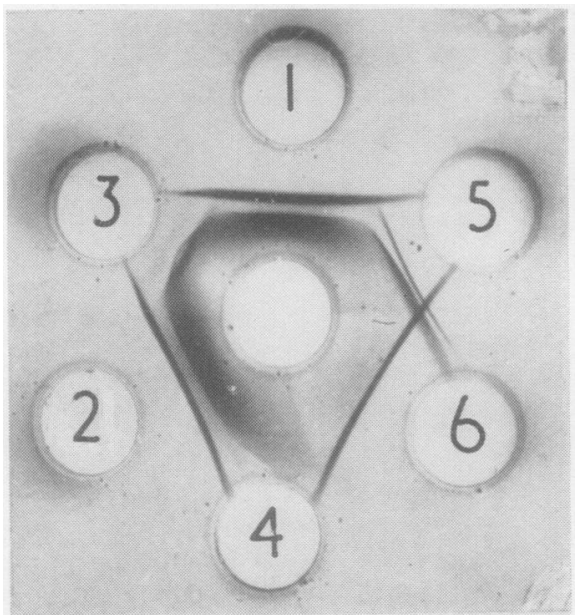

FIG. 10.-Abnormal globulin. 1, Normal serum. 2, Serum of patient Ed. 3, Fraction from serum of patient Ed. 4, Fraction similarly extracted from normal serum. 5, Fraction eluted from electrcphoretic strip of serum Ed. 6, Serum of Case 1 (a-gammaglobulinaemia): the antiserum is against normal human serum. The reaction is put up at relative " antigen excess" for most serum components. The reactions with 2 and 3 do not show the presence of the abnormal protein owing to interference by the $\gamma$-globulin reaction (the fluffy innermost line). The well-marked outer line is due to $\alpha_{2}$-globulin, removed by fractionation from 3,4 , and 5 . The sharp outermost line opposite 5 is due to an abnormal protein, which has here been concentrated relative to $\gamma$-globulin and therefore brought out clearly. Note that it is "deviated" by normal serum (1), though not by the a-gammaglobulinaemia serum (6), hence it must be present in normal serum (though at too low a concentration for its faint lire to appear on the photograph), a conclusion which is inevitable since antibodies to it have been provoked by the normal human serum used as the original antigen. But its metabolism is apparently linked in some way with $\gamma$-globulin, in spite of complete lack of serological cross-reaction, unless its absence from the a-gammaglobulinaemia serum is purely coincidental. with three parts of water, and had haemagglutinating properties, although it did not appear to be an antibody in the strict sense. The patient suffered from haemolytic anaemia, and the "haemagglutinin" was assumed to have something to do with this. The interesting point brought out is that this very unusual substance is evidently present in normal serum, in very low concentration, and is there strongly antigenic; not only does the antiserum raised against normal serum contain an appreciable amount of antibody against it, but it can actually be observed as a hitherto unidentified faint line in the normal serum pattern, very near the antigen source, i.e., in low concentration, but definitely joining with the line produced by the purified substance from the pathological serum.

Combination of Immunological Analysis with Electrophoresis. - The method described by Grabar and Williams (1953), in which antigen is electrophoretically separated in agar before the reaction with antiserum, is the one of choice in certain cases, but it suffers from some limitations for routine use : though technically fairly simple there are more things which can go wrong than in the petri-dish method, not more than two antigens can be directly compared. and those not side by side, it takes some 24 hours longer, and needs rather more antiserum.

The technique employed here is not quite identical $\overrightarrow{0}$ with that of the above authors, and will be describes or in a later publication. Essentially, however, a c electrophoretic run is carried out in a $3 \mathrm{~mm}$. layer $\delta \bar{\Phi}$. barbiturate buffer agar spread on a glass plate. Electrodes of platinum wire are contained in separate compartments : a filter paper bridge connects each of these compartments with a reservoir of buffer, and another connects this reservoir with one side of the agar on the plate ; using this method we have experienced no difficulties with $p \mathrm{H}$ changes, etc. One drop of the serum to be examined, and of a control normal serum (both containing a little bromphenol blue) are added to cups cut in the agar; a current (4-8 mA) is passed, sufficient to move the albumin (as marked by the blue dye) about $4 \mathrm{~cm}$. in $18 \mathrm{hr}$. Under these conditions the $\gamma$-globulin moves backwards with the endosmotic flow, $\beta$-globulins remain near the origin but are clearly separated, and the $\alpha_{2}$ - and $\alpha_{1}$ - are intermediate. After stopping the flow of current a trough is cut parallel with the direction of movement, 8-12 $\mathrm{mm}$. from the original cup, and this is filled with antiserum. Arcs of precipitate develop centred on the point of maximal concentration of the antigen concerned (Fig. 11).

For testing a pathological serum it is convenient to cut two cups $25 \mathrm{~mm}$. away from one another. one for the test serum and one for normal serum: at the conclusion of the run the trough can then be cut between them, and one can reasonably though not certainly conclude that arcs which are opposite one another represent identical components.

This is of particular value in the examination of the various sorts of $\gamma$-globulin. In agreement with Grabar we have found that these are not serologically 


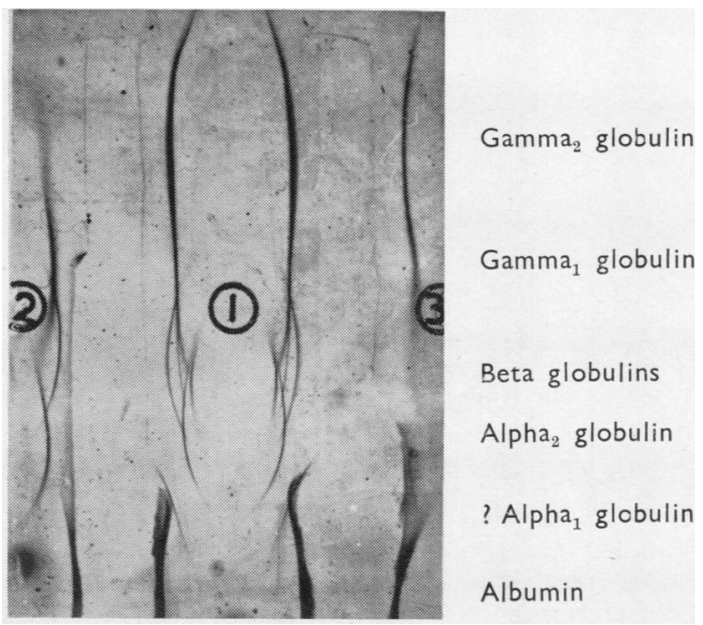

FIG. 11.-Immuno-electrophoretic method. 1, Normal serum. 2, Serum Ha., an undiagnosed case with hypoproteinaemia. 3, Serum Ta., a case of disseminated lupus erythematosus. The fractions are labelled on the right, at approximately the level of maximum concentration, i.e., the centre of the area formed by the precipitate: There is a striking deficiency of $\gamma_{2}$-globulin in 2 , and a less marked but still evident deficiency of $\gamma_{1}$-globulin in 3 . The $\alpha$ - and $\beta$-reactions in 3 do not appear, as the sample of serum was old and these fractions are apt to deteriorate on keeping at $4^{\circ} \mathrm{C}$. The albumin and $a_{1}$-reactions are unsatisfactory in this plate, for technical reasons.

differentiable; the gamma does not, however, form a true arc of precipitate with antiserum but an elongated and sometimes humped line. It is reasonable to equate these "humps" with the $\gamma_{1}$ and $\gamma_{2}$ globulins (or $\gamma$ and " $\beta_{2}$ " globulins), whose relationship is discussed by Oncley (1953): and the shape of the line can give some evidence as to their relative proportions. Routine analysis of a large number of sera from conditions showing abnormal values for "total $\gamma$ globulin," so as to differentiate between these fractions, should supply valuable data as to their pathogenesis. Fig. 11 shows an example of the application of the method to such an analysis.

\section{Discussion}

Once an antiserum has been raised and titrated, the immunological method of analysis has some advantage over more usual methods such as paper electrophoresis, though it is not likely to replace the latter for routine use. Its chief disadvantage is its lack of quantitative precision; and although as described above it is possible to adapt it to give a quantitative answer within 10 to $20 \%$ this necessitates the expenditure of some thought and possibly repeated tests, a more time-consuming process than a quantitative paper electrophoretic run, by a method such as that described by Hardwicke (1954). On the other hand, there are three great advantages which, recommend it as a method for investigating more thoroughly cases shown to be abnormal ; its very high sensitivity, valuable in cases of deficiency of a serum protein, its great discriminative power, demonstrating as it can more than 15 different fractions in normal serum as against the five to seven fractions of conventional electrophoretic techniques, and the fact that it depends upon biological or at least biochemical properties of a protein rather than upon the purely physical properties responsible for both the electrophoretic and the ultracentrifugal pattern. In general, immunological analysis by the geldiffusion method provides a valuable supplementary form of analysis, but cannot displace the usual electrophoretic techniques.

\section{Summary}

Methods are described for the laboratory analysis of human serum proteins by immunological and immuno-electrophoretic techniques, carried out in agar. Results in cases of a- and hypo-gammaglobulinaemia, the nephrotic syndrome, myelomatosis, etc., are described. Adaptations leading to semi-quantitative results are suggested.

\section{REFERENCES}

Bruton, O. C. (1952). Pediatrics, 9, 722

Elek, S. D. (1949). Brit. J. exp. Path., 30, 484.

Freund, J., and McDermott, K. (1942). Proc. Soc. exp. Biol., N.Y., 49, 548 .

Grabar, P. (1954). Bull. Soc. Chim. biol., Paris, 36, 65.

and Williams, C. A. (1953). Biochim. biophys. Acta, 10, 193. Grant, G. H., and Wallace, W. D. (1954). Lancet, 2, 671.

Hardwicke, J. (1954). Biochem. J., 57, 166.

Janeway, C. A., Apt. L., and Gitlin, D. (1953). Trans. Ass. Amer. Phys., 66, 200.

Kabat, E. A., and Mayer, M. M. (1948). Experimental Immunochemistry, pp. 543 and 544 . Thomas, Springfield, Illinois.

Munoz, J., and Becker, E. L. (1950). J, Immunol., 65, 47.

Oakley, C. L., and Fulthorpe, A. J. (1953). J. Path. Bact., 65, 49.

Oncley, J. L. (1953). In Blood Cells and Plasma Proteins, ed. Tullis, J. L., pp. 180-184. Academic Press, New York.

Ouchterlony, O. (1948). Acta path. microbiol scand., 25, 186. Ouchteriony, Ibid., 26, 507.

Oudin, J. (1946). C.R. Acad. Sci., Paris, 222, 115.

Young, I. I., and Wolfson, W. Q. (1954). Clin. Res. Proc., 2, 101. 